Bệnh nhân sốc nhiễm khuẩn là nhóm đối tượng nặng, tỉ lệ tử vong cao trong ICU. Sự xuất hiện đông máu nội quản rải rác dự báo kết cục xấu hơn trên nhóm bệnh nhân này. SFM có giá trị trong chẩn đoán DIC, làm tăng độ đặc hiệu, giá trị dự báo âm tính, giá trị dự báo dương tính so với D-Dimer tuy nhiên độ nhạy thấp hơn.

\section{TÀI LIẸU THAM KHẢO}

1. Opal S.M., Laterre P.-F., Francois B. và công sự. (2013). Effect of eritoran, an antagonist of MD2-TLR4, on mortality in patients with severe sepsis: the ACCESS randomized trial. Jama, 309(11), 1154-1162.

2. Park K.-J., Kwon E.-H., Kim H.-J. và cộng sự. (2011). Evaluation of the diagnostic performance of fibrin monomer in disseminated intravascular coagulation. Korean J Lab Med, 31(3), 143-147.

3. Nguyê̂n T.T. (2021). IDJặc Idjiểm lâm sàng, cận lâm sàng và một số yếu tố liên quan Idjên kết quả
Idjiều trị bệnh nhân sốc nhiễm khuẩn tại Bệnh viện Trung ương Thái Nguyên/Nguyễn Thanh Thủy. .

4. Gando S., Shiraishi A., Yamakawa K. và cộng sứ. (2019). Role of disseminated intravascular coagulation in severe sepsis. Thromb Res, 178, 182-188.

5. Quân N.H. nghiên cứu hiệu quả huyết động với sự hổ trợ của phqớng pháp picco trong xử trí sốc nhiếm khuẩn. 174.

6. Nguyễn Xuân N. (2009). Đánh giá hiệu quả của lọc máu liên tục trong điều trị suy đa tạng do sốc nhiếm khuẩn. .

7. Singh N., Pati H.P., Tyagi S. và cộng sự. (2017). Evaluation of the diagnostic performance of fibrin monomer in comparison to d-dimer in patients with overt and nonovert disseminated intravascular coagulation. Clin Appl Thromb, 23(5), 460-465.

8. Refaai M.A., Riley P., Mardovina T. và cộng sự. (2018). The clinical significance of fibrin monomers. Thromb Haemost, 118(11), 1856-1866.

\title{
ĐÁNH GIÁ HIỆU QUẢ CỦA PHÁC Đồ Có RITUXIMAB TRONG ĐIỀU TRI BƯớC ĐẦU U LYMPHO THỂ NANG TẠI BỆNH VIỆN K
}

\section{Nguyễn Tiến Quang ${ }^{1}$, Đỗ Huyền Nga ${ }^{1}$, Nguyễn Thanh Tùng ${ }^{1}$}

\section{TÓM TẮT}

Mục tiêu: Đánh giá hiệu quả của phác đồ có Rituximab trong điều trị bước đâu u lympho thể nang tại bệnh viện $K$. Đối tượng và phương pháp: Nghiên cứu mô tả tiến cứu trên 24 bệnh nhân u lympho thể nang điều trị bước đầu bằng phác đồ có rituximab từ tháng $5 / 2019$ đến tháng $10 / 2021$. Kết quả: Độ tuổi trung bình của bệnh nhân là 59,71 , tỉ lệ giới tính trong nghiên cứu là nam/nữ $=2$, đa số bệnh nhân vào viện vì nổi hạch 70,7\%; đa số bệnh nhân ở giai đoan 3 chiếm $62 \%$; nhóm điêuu trị bằng phác đồ RB có tỉ lệ đáp ứng toàn bộ $100 \%$. nhóm điều trị bằng $\mathrm{RCHOP} / \mathrm{RCVP}$ có tỉ lê đáp ứng toàn bộ là $87,4 \%$. Tỉ lế bệnh nhân gặp độc tính khi điều trị phác đổ RCंHOP/RCVP 75\% trong khi nhóm điêu trị RB chỉ găp độc tính 25\%. Kết luận: Phác đồ RB cho tỉ lệ đáp ứng và tính an toàn cào hơn phác đồ RCHOP/RCVP trong điều trị bước đầu u lympho thể nang.

Tư khóa: u lympho thể nang

\section{SUMMARY \\ ASSESSMENT THE EFFECTIVENESS OF RITUXIMAB REGIMENS IN THE FIRST LINE TREATMENT OF FOLLICULAR LYMPHOMA AT K HOSPITAL}

\footnotetext{
*Bệnh viện $K$

Chịu trách nhiệm chính: Nguyễn Tiến Quang

Email: ntienquangbvk@gmail.com

Ngày nhận bài: 14.9.2021

Ngày phản biện khoa học: 10.11.2021

Ngày duyệt bài: 17.11.2021
}

Objectives: To evaluate the effectiveness of a rituximab regimens in the first line treatment of follicular lymphoma at K hospital. Subjects and methods: A prospective descriptive study conducted on 24 follicular lymphoma patients treated with rituximab regimens from May 2019 to October 2021. Results: The average age of the patients was 59.71 , the sex ratio male/female was 2.0 , almost patients were hospitalized because of lymphadenopathy $70.7 \%$; almost patient have stage 3 accounted for $62 \%$; The overall response rate of RB group was $100 \%$. The overall response rate of RCHOP/RCVP group was $87.4 \%$. The toxicity rate of RCHOP/RCVP group was $75 \%$ while the toxicity rate of the RB group was $25 \%$. Conclusion: The RB regimen has a higher response rate and safety than the RCHOP/RCVP regimen in the first line treatment of follicular lymphoma.

Key words: follicular lymphoma (FL)

\section{I. ĐẶT VẤN ĐỀ}

U lympho dạng nang (FL-Follicular Lymphoma) là loại u lympho không Hodgkin (NHL-non Hodgkin lymphoma) phổ biến thứ hai chiếm khoảng 20\%-35\%. Đây là bệnh phổ biến nhất trong số các NHL tiến triển chậm trên lâm sàng ${ }^{1}$.

Ở Hoa Kỳ, FL chiếm khoảng $35 \%$ các NHL và có tỷ lệ mắc ước tính là 3,18 trường hợp trên 100.000 người. Tỷ lệ mắc bệnh ổn định theo thời gian, nhưng thay đổi theo chủng tộc, với tỷ lệ mắc bệnh ở người da trắng cao hớn hai lân so với dân số châu Phi và châu Á. Tỉ lệ mắc bệnh tương đương ở hai giới. Tỉ lệ mắc bệnh tăng dân 
theo tuổi; FL thường xuất hiện nhất ở người trung niên và người cao tuổi, với độ tuổi trung bình được chẩn đoán là 65 tuổi. Hiếm khi FL phát sinh ở trẻ em hoặc thanh thiếu niên?2.

U lympho thể nang thường phát triển trong thời gian kéo dài ít gây triệu chứng lâm sàng. Quyết định điều trị u lympho thể nang phụ thuộc vào giai đoạn bệnh khi chẩn đoán. Đối với u lympho thể nang giai đoạn I chỉ định điều trị xạ trị giúp kéo dài thời gian sống thêm không bệnh tiến triển. Bệnh nhân u lympho thể nang giai đoạn III và IV (giai đoạn tiến xa) thường được điều trị giống như điều trị bệnh mạn tính với mục tiêu trọng tâm là kiểm soát triệu chứng. Các bệnh nhân giai đoạn III và IV sẽ nhận được điều trị hóa trị hoăc xạ trị hoặc phối hợp đa mô thức để kiểm soát phát triển bệnh trong thời gian dài, ${ }^{3}$. Mặt khác đối với u lympho thể nang độ mô học 3 lựa chọn điều trị sẽ giống như thể tiến triển nhanh với phác đồ ưu tiên là RCHOP.

Trong điều trị u lympho thể nang, rituximab kết hợp với hóa trị liệu là lựa chọn hàng đầu để cải thiện về tỷ lệ đáp ứng, tỳ lệ sống không bệnh tiến triển và tỳ lệ sống còn toàn bộ ${ }^{3}$. Những năm gần đây phác đồ bendamustin kết hợp với rituximab đã được sử dụng trong điều trị u lympho không Hodgkin thế nang 4 .

\section{II. ĐỐI TƯỢNG VÀ PHƯƠNG PHÁP NGHIÊN CỨU \\ * Đối tượng nghiên cứu}

a, Tiêu chuẩn lựa chọn. Tất cả các bệnh nhân được chẩn đoán u lympho không Hodgkin thể nang tại bệnh viện $\mathrm{K}$ đáp ứng các tiêu chuẩn chọn mẩu sau:

- Từ đủ 18 tuổi trở lên.

- Chẩn đoán lân đầu là u lympho không Hodgkin thể nang và chưa điều trị hóa - xạ trị trước.

- Kết quả giải phẫu bệnh cho hình ảnh vi thể và nhuộm hóa mô miễn dịch chẩn đoán xác định u lymphokhông Hodgkin thể nang, CD 20 (+)

- PS = 0 -> 2; Công thức máu bình thường; Mức lọc cầu thận $\geq 50 \mathrm{ml} /$ phút; AST/ALT $\leq 2,5 \mathrm{x}$ ngưỡng giới hạn.

- Bệnh nhẩn có tiêu chuẩn cần phải điều trị: (1) Triệu chứng do hạch lớn hoặc chèn ép tại chồ; (2), Hạch gây ảnh hưởng tới chức năng các cơ quan; (3), Hội chứng B; (4),Bệnh biểu hiện cơ quan ngoài hạch; (5), Suy giảm các dòng tể bào máu do xâm lấn tủy xương, thiếu máu tan máu, giảm tiểu cầu, tăng hoạt động của lách; (5), bệnh tiến triển nhanh.

\section{b, Tiêu chuấn loai trừ \\ - Bênh chuyển thể \\ - Có bệnh lý ác tính trong vòng 3 năm}

- Rối loạn tim mạch: suy tim độ III, IV, nhồi máu cơ tim trước đó 6 tháng

- Anti - HIV (+), dấu hiệu hoạt động của $\mathrm{HBV}, \mathrm{HCV}$.

- Phụ nữ có thai hoăc cho con bú.

*Phương pháp nghiên cứu: Nghiên cứu mô tả tiến cứu được tiến hành trên 24 bệnh nhân u lympho thể nang điều trị bằng phác đồ có rituximab từ tháng $05 / 2019$ đến tháng 10/2021 tại Khoa Nội Hệ tạo Huyết - Bệnh viện K3 cơ sở Tân Triêu

*Các thông số nghiên cứu

- Đặc điểm lâm sàng của bệnh nhân trước điều trị: tuổi, giới, triệu chứng lẩm sàng, chỉ số tiên lượng.

- Đặc điểm cận lâm sàng: CT scan (hoặc $\mathrm{PET} / \mathrm{CT}$ ), đặc điểm giải phẫu bệnh khối u

- Đáp ứng điều trị sau 3 đợt, 6 đợt điều trị.

- Đánh giá tác dụng phụ của thuốc.

*Quy trình nghiên cứu

- Bước 1: Lựa chọn bệnh nhân tham gia nghiên cứu.

- Bước 2: Tiến hành điều trị bệnh nhân theo phác đồ R-B/RCHOP/RCVP.

- Bước 3: Thu thập và xử lý số liệu.

- Bước 4: Hoàn thiên đề tài.

* Phân tích và xử lý số liệu

Các thông tin được mã hoá và xử lý bằng phần mềm SPSS 16.0

* Khía cạnh đạo đức của nghiên cứu

Đây là nghiên cứu có tính chất can thiệp điều trị, thuốc Rituximab, Bendamustin, Cyclophosphamide, Doxorubicin, Vincristine đã được đưa vào hướng dẫn điều trị u lympho không Hodgkin của Bộ Y Tế Việt Nam. Nghiên cứu này chỉ nhằm mục đích nâng cao chất lượng điều trị, không nhằm mục đích nào khác.

\section{KẾT QUẢ NGHIÊN CứU}

Bảng 1. Đặc điểm chung của đôî tượng nghiên cứu

\begin{tabular}{|c|c|c|}
\hline \multicolumn{2}{|c|}{ Đặc điểm (n= 24) } & $\begin{array}{l}\text { Trung bình } \pm \text { SD } \\
\text { (nhỏ }\end{array}$ \\
\hline \multicolumn{2}{|c|}{ Tuối } & $59,71 \pm 9,39(33-78)$ \\
\hline \multirow{2}{*}{ Giới } & Nam & $16(66,7 \%)$ \\
\hline & Nữ & $8(33,3 \%)$ \\
\hline \multicolumn{2}{|c|}{ Chiều cao (cm) } & $159,17 \pm 6,54(145-170)$ \\
\hline \multicolumn{2}{|c|}{ Cân nặng $(\mathrm{kg})$} & $53,13 \pm 6,02(41-63)$ \\
\hline \multicolumn{3}{|c|}{ BMI } \\
\hline Bình thường & $18,5-22,9$ & $20(83,3)$ \\
\hline Thừa cân & $23-24,9$ & $4(16,7)$ \\
\hline \multicolumn{2}{|c|}{ Diện tích da } & $1,53 \pm 0,11(1,28-1,68)$ \\
\hline \multirow{2}{*}{ PS } & 0 & $17(70,8)$ \\
\hline & 1 & $7(29,2)$ \\
\hline
\end{tabular}




\begin{tabular}{|c|c|}
\hline (2) & 0 \\
\hline $\begin{array}{l}\text { Hội chứng B } \\
\end{array}$ & $2(8,3)$ \\
\hline \multicolumn{2}{|c|}{ Bảng 2. Lý do vào viênn } \\
\hline Lý do vào viện & n (\%) \\
\hline Nối hạch & $17(70,7)$ \\
\hline Nối u hốc mắt & $1(4,2)$ \\
\hline Đau bụng & $3(12,5)$ \\
\hline Đau lưng & $1(4,2)$ \\
\hline Bí đái & $1(4,2)$ \\
\hline Ho, khó thở & $1(4,2)$ \\
\hline
\end{tabular}

Phân loại mô bệnh học

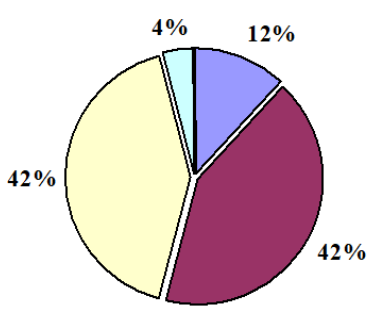

$\square$ Thểnang độ $1 \square$ Thểnang độ $2 \square$ Thểnang độ $3 \mathrm{~A} \square$ Thểnang độ 3B

Biểu đồ 1. Phân loại mô bệnh học

Bảng 3. Tỉ lê hach theo nhóm và vị trí ngoài hạch

\begin{tabular}{|c|c|}
\hline Vị trí biếu hiện & n (\%) \\
\hline Hạch ngoại vi & $23(95,8)$ \\
\hline Cố & $20(83,3)$ \\
\hline Nách & $12(50,0)$ \\
\hline Bẹn & $6(25,0)$ \\
\hline Hốc mắt & $1(4,2)$ \\
\hline
\end{tabular}

\begin{tabular}{|c|c|}
\hline Khối bả vai trái & $1(4,2)$ \\
\hline Tuyến dưới hàm & $1(4,2)$ \\
\hline Hạch trung tâm & $19(79,2)$ \\
\hline Trung thất & $11(45,8)$ \\
\hline Ó bụng & $18(75,0)$ \\
\hline Vị trí ngoài hạch & $3(13,6)$ \\
\hline Lách & $2(8,3)$ \\
\hline Đại tràng & $1(4,2)$ \\
\hline Phối & $1(4,2)$ \\
\hline
\end{tabular}

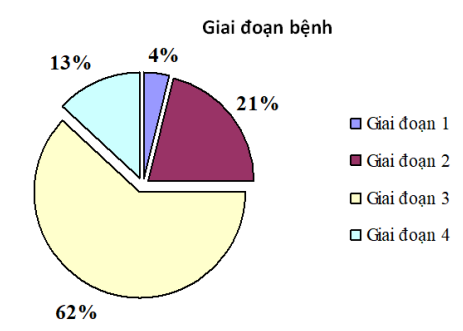

Biểu đồ 2. Giai đoạn bệnh

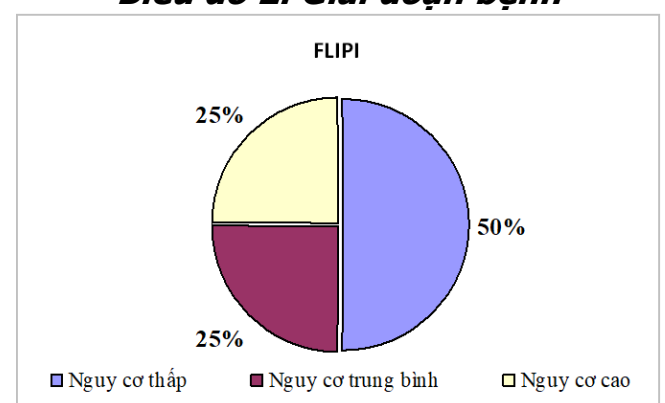

Biểu đồ 3. Điểm số tiên lượng FLIPI

\section{Bảng 4. Tỉ lệ đáp ứng}

\begin{tabular}{|c|c|c|c|c|}
\hline Phân loại đáp ứng & $\begin{array}{c}\text { RB } \\
(n=8)\end{array}$ & $\begin{array}{c}\text { RCHOP/RCVP } \\
(n=16)\end{array}$ & $\begin{array}{l}\text { Chung } \\
(n=24)\end{array}$ & p \\
\hline Đáp ứng hoàn toàn (CR) & $4(50,0)$ & $9(56,2)$ & $13(54,2)$ & \multirow{5}{*}{0,05} \\
\hline Đáp ứng một phần (PR) & $4(50,0)$ & $5(31,2)$ & $9(37,5)$ & \\
\hline Bênh giữ nquyên (SD) & 0 & 0 & 0 & \\
\hline Bệnh tiến triến (PD) & 0 & $2(12,5)$ & $2(8,3)$ & \\
\hline Tỉ lê đáp ứng toàn bộ (CR+PR) & $8(100)$ & $14(87,4)$ & $22(91,7)$ & \\
\hline
\end{tabular}

Tỉ lệ đáp ứng toàn bô (CR+PR)

\section{Bảng 5. Độc tính}

\begin{tabular}{|c|c|c|c|c|}
\hline Độc tính (n=24) & $\begin{array}{c}\text { RB } \\
(\mathbf{n = 8 )}\end{array}$ & $\begin{array}{c}\text { RCHOP/RCVP } \\
\mathbf{( n = 1 6 )}\end{array}$ & $\begin{array}{c}\text { Chung } \\
\mathbf{( n = 2 4 )}\end{array}$ & $\mathbf{p}$ \\
\hline Tỉ lệ bệnh nhân gặp độc tính độ 3 trở \\
lên (trứ rụng tóc) & $2(25,0)$ & $12(75,0)$ & $14(58,3)$ & $\mathbf{0 , 0 3}$ \\
\hline Hạ bạch cầu độ 3-4 & $2(25,0)$ & $11(68,8)$ & $13(54,2)$ & 0,08 \\
\hline Sốt hạ bạch câu & $1(12,5)$ & $4(25,0)$ & $5(20,8)$ & 0,63 \\
\hline Độc tính hệ tiếu hóa & 0 & $5(31,2)$ & $5(20,8)$ & 0,13 \\
\hline Viêm phối & 0 & $3(18,8)$ & $3(12,5)$ & 0,52 \\
\hline Rụng tóc & 0 & $14(87,5)$ & $14(58,33)$ & $<0,001$ \\
\hline
\end{tabular}

\section{BÀN LUÂ̂N}

\section{1. Đặc điểm chung của bệnh nhân}

Tuổi và giới. U lympho không Hodgkin thể nang thường gặp ở độ tuổi khoảng 65 , có một số ít trường hợp bệnh ở trẻ em hoặc thanh thiếu niên. Tỉ lệ bệnh ở nam và nữ tương đương nhau ${ }^{2}$. Nghiên cứu của chúng tôi thu được độ tuổi trung bình của bệnh nhân là 59,71 \pm 9,39 (nhỏ nhất 33 tuổi - lớn nhất 78 tuổi). Tỉ lệ giới tính trong nghiên cứu là nam/nữ=2. Nghiên cứu 
của chúng tôi có độ tuổi tương đương với các tác giả khác tuy nhiên tỉ lệ giới tính nam trong nghiên cứu của chúng tổi lại cao hơn như: tác giả Takashi $2018^{5}$, tác giả Ganguly Siddhartha $2009^{6}$, tác giả Mondello $2016^{7}$.

Thông số nhân trắc. Kết quả phân tích thu được chiều cao trung bình của bệnh nhân là $159,17 \pm 6,54 \mathrm{~cm}$; cân nặng trung bình của bệnh nhân là $53,13 \pm 6,02 \mathrm{~kg}$. Chỉ số BMI của bệnh nhân đa phần trong ngưỡng bình thường chiếm $83,3 \%$, có $16,7 \%$ bệnh nhân thừa cân. Diện tích da trung bình của bệnh nhân là 1,53 \pm $0,11 \mathrm{~m} 2$. Thông số nhân trắc chúng tôi thu được tương đương với thông số nhân trắc bình thường của người Việt Nam.

Lý do vào viện. Nghiên cứu của chúng tôi ghi nhận đa số bệnh nhân vào viện vì nổi hạch $70,7 \%$, tỉ lệ bệnh nhân nhập viện vì đau bụng là $12,5 \%$, nổi u hốc mắt hoặc đau lưng hoặc bí đái hoặc ho, khó thở chiếm 4,2\%. Toàn trạng bênh nhân khi vào viện đa phần ở mức $\mathrm{PS}=0$ chiếm $70,8 \%$ và có $29,2 \%$ bệnh nhân có $P S=1$.

Hạch và vị trí ngoài hạch. Nghiên cứu của chúng tôi thu được tỉ lệ bệnh nhân có hạch ngoại vi chiếm 95,8\% trong đó: hạch cổ chiếm tỉ lệ cao nhất $83,3 \%$, kế tiếp là hach nách $50 \%$, hạch ben $25 \%$, ngoài ra còn có biểu hiện tại các vị trí hiếm gặp như hốc mắt hoặc khối vùng phần mềm bả vai trái hoặc tuyến dưới hàm chiếm $4,2 \%$. Tỉ lệ bệnh nhân có hạch ở trung tâm chiếm 79,2\% trong đó có $45,8 \%$ bệnh nhân có hạch trung thất và $75,0 \%$ bệnh nhân có hạch ổ bụng. Tỉ lệ bệnh nhân có biểu hiện ngoài hạch là $13,6 \%$ trong đó có $8,3 \%$ có tổn thương tại lách, $4,2 \%$ bệnh nhân có tổn thương đại tràng và $4,2 \%$ bệnh nhân có tổn thương phổi.

Mô bệnh học. Trong nghiên cứu của chúng tôi thu được tỉ lệ mô học thể nang độ 1 chiếm $12 \%$, thể nang độ 2 chiểm $42 \%$, thể nang độ $3 \mathrm{~A}$ chiếm $42 \%$, thể nang độ $3 B$ chiếm $4 \%$.

Giai đoạn bệnh. Dưa theo phân giai đoạn của Lugano, qua phân tích chúng tôi thu được tỉ lệ bệnh nhân ở giai đoạn 1 chiếm 4\%, giai đoạn 2 chiếm $21 \%$, giai đoạn 3 chiếm $62 \%$, giai đoạn 4 chiếm $13 \%$. Đa phần các bênh nhân đến viển ở giai đoạn 3 hoặc 4 và có triệu chứng bắt buộc phải điều trị theo thang điểm GELF. Chúng tôi có 1 bệnh nhẩn ở giai đoạn 1 biểu hiện ở tuyến dưới hàm tuy nhiên giải phẫu bệnh của bệnh nhân là u lympho thể nang độ $3 \mathrm{~A}$ nên bắt buộc phải điều trị sớm bằng phác đồ $\mathrm{RCHOP}$ với thái độ xử trí như một bệnh u lympho tế bào $B$ lớn lan tỏa.

Thang điểm tiên lượng. Khi chấm điểm tiên lượng theo thang FLIPI chúng tôi thu được kết quả tỉ lệ bệnh nhân có điểm FLIPI $=0$ chiếm $21 \%$, FLIPI $=1$ chiếm $29 \%$, FLIPI $=2$ chiếm $25 \%$, FLIPI $=3$ chiếm $25 \%$ và không có bênh nhân nào điểm FLIPI đạt 4-5. Như vậy tỉ lệ bệnh nhân ở nhóm nguy cơ thấp FLIPI $0-1$ là $50 \%$, nguy cơ trung bình FLIPI 2 là $25 \%$ và nguy cơ cao FLIPI 3 là $25 \%$. Nghiên cứu của chúng tôi cho tỉ lệ bệnh nhân ở nhóm nguy cơ cao thấp hơn nghiên cứu của tác giả Flinn 20148; tác giả Mondello 20167.

\subsection{Hiệu quả phác đồ và tác dụng} không mong muốn

Hiệu quá phác đồ. Trong nghiên cứu của chúng tôi bệnh nhân được chia làm 2 nhóm điều trị bằng phác đồ $R B \quad 8 / 24$ và phác đồ RCHOP/RCVP 16/24 trong đó nhóm điều trị bằng phác đồ RB có tỉ lệ đáp ứng hoàn toàn là $50 \%$, đáp ứng 1 phần là $50 \%$, tỉ lệ kiểm soát bệnh $100 \%$. Mặt khác nhóm điều trị bằng RCHOP/ RCVP có tỉ lệ đáp ứng hoàn toàn là $56,2 \%$, tỉ lê đáp ứng một phần là $31,2 \%$ và có $12,5 \%$ bệnh nhân bị tiến triển, tỉ lệ kiểm soát bệnh là $87,4 \%$. Tuy nhiên sự khác biệt về tỉ lệ đáp ứng giữa hai nhóm không có ý nghĩa thống kê với $p>0,05$. Nghiên cứu của chúng tôi cho tỉ lệ đáp ứng tương đương với các nghiên cứu của: Ganguly Siddhartha 20096; Flinn 20148; Mondello 20167.

Độc tính. Nghiên cứu của chúng tôi thu được tỉ lệ bệnh nhân gặp độc tính là $58,3 \%$ trong đó bệnh nhân gặp độc tính ngoài rụng tóc khi điều trị phác đồ RCHOP/RCVP chiếm tỉ lệ cao $75 \%$ trong khi nhóm điêu trị RB chỉ gặp độc tính trong $25 \%$ trường hợp. Sự khác biệt về tỉ lệ gặp độc tính ở 2 nhóm có ý nghĩa thống kê với $p<0,05$. Tì lệ biến chứng ha bach cầu ở nhóm điều trị RB là $25 \%, \mathrm{RCHOP} / \mathrm{RCHOP}$ là $68,8 \%$. Nhóm điều trị bằng RB không gặp các độc tính trên hệ tiêu hóa, viêm phổi, rụng tóc trong khi tỉ lệ này ở nhóm điều trị RCHOP/RCVP tương ứng là $31,2 \%$; $18,8 \% ; 87,5 \%$. Trong đó tất cả các bệnh nhân điều trị phác đồ RCHOP đều bị rụng tóc 14/16 trong khi 2 bệnh nhân điều trị phác đồ RCVP không gặp độc tính này. Tî lệ độc tính trong nghiên cứu của chúng tôi tương đương với tác giả Flinn 20148; Mondello $2016^{7}$.

\section{KẾT LUÂN}

Như vậy kết quả nghiên cứu của chúng tôi về hiệu quả và độc tính tương đương với các tác giả khác trên thế giới. Phác đồ RB có hiệu quả ưu việt về kiểm soát bệnh và ít độc tính hơn so với phác đồ cổ điển RCHOP. Tuy nhiên phác đồ RB chỉ được ưu tiên lựa chon khi điều trị u lympho thể nang độ ác tính thẩp, độ mô học 1-2, mặt 
khác đối với u lympho thể nang độ 3 nên lựa chọn điêu trị như một u lympho tế bào $\mathrm{B}$ lớn lan tỏa bằng phác đồ RCHOP.

\section{TÀI LIỆU THAM KHẢO}

1. Trân Văn Thuấn. Hướng dẫn chẩn đoán và điều trị bệnh ung thư thường gặp. Nhà xuất bản Y học. 2019:5-24.

2. Arnold S Freedman. Clinical manifestations, pathologic features, and diagnosis of mantle cell lymphoma. Uptodate. 2021:1-14.

3. Andrew D.Z. NCCN Clinical practice guidelines in Oncology - B-Cell lymphomas. NCCN. 2020:12-65.

4. Mondello $\mathbf{P}$. et al. Bendamustine plus rituximab versus R-CHOP as first-line treatment for patients with indolent non-Hodgkin's lymphoma: evidence from a multicenter, retrospective study. Ann
Hematol. 2016;95(7):1107-1114.

5. Takashi Watanabe. Outcomes after R-CHOP in patients with newly diagnosed advanced follicular lymphoma: a 10-year follow-up analysis of the JCOG0203 trial. Lancet Haematol. 2018:520-531.

6. Ganguly Siddhartha, Patel Vijay. R-CHOP versus R-CVP in the treatment of follicular lymphoma: a meta-analysis and critical appraisal of current literature. J Hematol Oncol 2009:14-19.

7. Mondello $\mathbf{P}$. Bendamustine plus rituximab versus R-CHOP as first-line treatment for patients with indolent non-Hodgkin's lymphoma: evidence from a multicenter, retrospective study. Ann Hematol. 2016;(7)(95):1107-1114.

8. Flinn I. W. Randomized trial of bendamustinerituximab or R-CHOP/R-CVP in first-line treatment of indolent NHL or MCL: the BRIGHT study. Blood Journal. 2014;123(19):2944-2952.

\section{BÁO CÁO TRƯờNG HợP DI VẬT HIẾM GẶP Ở SỤN PHỄU GÂY ÁP XE SỤN PHỄU}

\section{TÓM TẮT}

Tháng 5/ 2021, bệnh nhân nam, 55 tuổi, nhập viện vì nuốt đau. Bệnh nhân khai có nuốt ăn cá và hóc xương, nuốt đau, ngày càng tăng, ăn uống khó. Nội soi thực quản ống mềm ghi nhận phù nề vùng niêm mạc sụn phễu bên trái và 1 lổ thủng trên niêm mạc. CT'scan vưng cổ ghi nhận thây dị vật cản quang dạng đường thẳng, dài $2,8 \mathrm{~cm}$, nằm trên mức sụn nhẫn. Bệnh nhân được gây mê, nội soi đánh giá vùng hạ họng thanh quản dưới nội soi thấy phù nề vùng xoang lề trái, có 1 lố dò nghi ngờ đường vào của dị vật. Kết hợp nội soi, phẫu thuật viên sử dụng dụng cụ vi phẫu mở rộng đường vào, thám sát đáy vết thương thấy di vật xương cá.

Tư khóa: dị vật xương cá, dị vật ở sụn phễu

\section{SUMMARY \\ RARELY CASE REPORT: FOREIGN BODY OF ARYTENOID CARTILAGE CAUSING ABSCESS}

A 55 years old patient visited to Cho Ray hospital in May, 2021 with painful swallowing. The patient had painful swallowing while he ate fish. He felt pain every swallowing. Result of fexible endoscopy was edema of left arytenoid cartilage mucosa. CTscan shown straight foreign body in arytenoid cartilage with $2.8 \mathrm{~cm}$ length. And then, he was operated to remove foreign body from arytenoid cartilage with general anesthesia. Foreign body was straight, long fish bone.

*Bênhh viên Chơ Rẫy

Chịu trách nhiệm chính: Ngô Văn Công

Email: congtmh@gmail.com

Ngày nhận bài: 15.9.2021

Ngày phản biên khoa học: 15.11.2021

Ngày duyệt bài: 23.11.2021
Ngô Văn Công*

Key words: fish bone foreign body, forgein body in arytenoid cartilage.

\section{GIỚI THIÊUU}

Dị vật đường tiêu hóa trên là một trong những cấp cứu thường gặp của Tai Mũi Họng. Dị vật thực quản thường gặp ở trẻ em và người lớn, trong đó dị vật xương động vật (đặc biệt là xương cá) chiểm ưu thế ở người lớn [1]. Theo hướng dấn dị vật đường ăn của Hội Nội Soi Đường Tiêu Hóa Hoa Kỳ thì dị vật thường đi qua thực quản và ra ngoài theo đường tiêu hóa, khoảng $10-20 \%$ cần can thiệp lấy dị vật qua nội soi và dưới $1 \%$ cần can thiệp phẫu thuật [2]. Di vật thường tắc nghẽn tại những chỗ hẹp sinh lî của thực quản. Các di vật lớn hoăc kích thước bất thường thường gây chèn ép lền niêm mạc thực quản làm phù nề, thiếu máu, hoại tử niêm mạc. Thủng thực quản là biến chứng đe dọa tính mạng và thường thấy ở dị vật sắc nhọn và xương động vật (xương cá). Các biến chứng bao gồm loét thực quản, rách thực quản, thủng thực quản, áp xe do dị vật, ... [6]

\section{BÁO CÁO TRƯỜNG HỢP LÂM SÀNG:}

Bệnh nhân nam, 55 tuổi, nhập viện vì nuốt đau ngày 28 tháng 5 năm 2021. Bệnh nhân khai đã hóc xương cá 1 ngày trước, được khám và chì định nội soi thực quản ống mềm. Kết quả nội soi thực quản ống mềm ghi nhận phù nề vùng xoang lê trái, không ghi nhận dị vật qua nội soi.

Sau đó, bệnh nhân được chỉ định chụp CTscan vùng cổ ghi nhận thấy dị vật cản quang 